\title{
Synthesis and adsorption properties of Chitosan cross linked with phenol - formaldehyde resin for the removal of heavy metals and dyes from water
}

\author{
M. Ilayaraja ${ }^{\mathrm{a}}$, S. Sharmilaparveen ${ }^{\mathrm{a}}$, R. Sayeekannan ${ }^{\mathrm{a} *}$ \\ ${ }^{a} P G$ Research and Department of chemistry, Thiagarajar college, Madurai-625009,Tamil Nadu, India.
}

\begin{abstract}
A novel activated carbon material has been prepared by carbonization and activation of PhenolChitosan-Formaldehyde resin (PCFR) which synthesized by the condensation polymerization method. The physicochemical properties of the PCFR were characterized by SEM, XRD, BET, EDS, TGA and FTIR spectroscopy. The adsorption properties of $P b(I I)$ ion and Methylene blue (MB) onto PCFR were investigated by batch techniques. The particle size of adsorbent was 65-70 $\mu$. Kinetic studies indicated that Pb(II) ion and $M B$ adsorption followed the pseudo-second-order model. The adsorption may be controlled by external mass transfer followed by intra-particle diffusion mass transfer. Equilibrium adsorption was investigated by the Langmuir, Freundlich, Temkin, D-R and Jovanoic isotherms. The thermodynamics parameters of adsorption systems indicated spontaneous and endothermic process.
\end{abstract}

Keywords:TGA, Lead ion, Methylene blue, Adsorption, Kinetics

\section{Introduction:}

The contamination of water from toxic compounds, like heavy metal ions and dyes remains a severe environmental and public problem. Heavy metal ions and dyes are often found in the environment as a result of increasing industrial use. They are common contaminants in waste water and known to be toxic and carcinogenic [1]. Lead ion is emitted into the atmosphere by the combustion of fossil fuels, batteries and the smelting of sulfide ores, and in lakes and streams by acid mine drainage [2]. $\mathrm{Pb}$ (II) ions dominates in acid while $\mathrm{PbOH}^{+}$predominates in most environmental pHs. The permissible limit of lead ion in drinking water and surface water intended for drinking, as set by EU and WHO, are 0.010 and $0.010 \mathrm{mg} / \mathrm{L}$, respectively [3-4]. Dyes are widely used in textile, paper, plastics coating, etc. The presence of dyes in water consumes oxygen and elevates biochemical oxygen demand destroying the aquatic life [5].

Various technologies and processes are currently used to remove such pollutants from wastewater, like biological treatments, membrane processes, advanced oxidation processes, chemical and electrochemical techniques and adsorption [6-9]. Amongst all, adsorption technique is a feasible option, both technically and economically. Especially, if the adsorbent is inexpensive and readily available then adsorption process provides as an alternative.

The application of biopolymers such as chitosan is one of the most emerging adsorption methods for the removal of dyes and heavy metal ion, even at low concentrations [10]. Chitosan derivatives contain nitrogen, phosphorus and sulfur as heteroatoms. Recently, chitosan composites have been developed to adsorb heavy metals and dyes from wastewater. Various substances have been used to form composite with chitosan such as montmorillonite [11], polyurethane [12], poly vinyl alcohol, poly vinyl chloride and kaolinite [13].

The aim of this work is to improve adsorption capacity of Chitosan by grafting Phenol-Formaldehyde resin on its surface to adsorb lead ion and methylene blue dye and to illustrate adsorption processes and evaluate the feasibility of applying modified PCFR as an adsorbent and ion exchange in practical heavy metal and dye removal. Different physiochemical parameters, i.e., initial concentration of metal ion and dye solutions, adsorbent dose, contact time and temperature were also investigated. To predict the nature of the adsorption process, the equilibrium, kinetics and thermodynamic studies were investigated.

\subsection{Materials:}

\section{Materials and Methods:}

The chemicals Con. sulfuric acid (Specific gravity $=1.82)$, Formaldehyde $(37-40 \%$ solution) and Phenol (Density $=1.057 \mathrm{gm}^{-1}$ ) were used in the present study. Chitosan (Chitosan, degree of deacetylation $85 \%$, average molecular weight $\left.-9.0 \times 10^{5}\right)$ was supplied by Merck India. The dye $\mathrm{MB}\left(\mathrm{C}_{16} \mathrm{H}_{18} \mathrm{ClN}_{3} \mathrm{~S} .3 \mathrm{H}_{2} \mathrm{O}\right.$, molecular weight-373.9) and Lead nitrate (M.W. 331.21) was obtained from RANKEM chemicals, New Delhi, India. All the chemicals used were analytical grade. The double distilled water was used throughout the investigation. 


\subsection{Preparation of PCFR composites:}

Phenol and Con. Sulfuric acid (1:1) and $0.5 \mathrm{mg}$ of Chitosan were mixed slowly with constant stirring in an ice bath. The mixture was then, heated to $70^{\circ} \mathrm{C}$ for three hours, cooled and kept overnight. The product was polymerized with formaldehyde solution $(12 \mathrm{ml})$ in an ice bath, and then heated to $70^{\circ} \mathrm{C}$ for three hours and the product was cured, then ground washed with DD water, to remove the free acid. Then the sample was dried at $70^{\circ} \mathrm{C}$ for $16 \mathrm{~h}$. Then the composite resin was sieved and preserved for characterization and further studies.

\subsection{Adsorption Experiments}

Batch mode adsorption studies were carried out by adding certain amount of adsorbent and 50ml of dye and $40 \mathrm{ml}$ of metal ion solutions of certain concentrations, dose, contact time and temperatures in a thermo stated water bath shaker with a shaking of 200rpm. Thesamples were withdrawn from the shaker at predetermined time intervals and solutions were separated from the adsorbent by centrifugation at 4000rpm for $5 \mathrm{~min}$. To determine the residual dye concentration, the absorbance of the supernatant solution was measured before and after treatment with double beam spectrophotometer (JASCO V530 Spectrophotometer). Lead ion concentration was measured using atomic absorption (Elico SL-173) spectrometry at wavelength of $283.3 \mathrm{~nm}$, experiments were carried out twice and the concentrations given were average values. The initial dye and metal ion concentrations in the test solution and the contact time were changed to investigate their effect on the adsorption kinetics. The $\mathrm{pH}$ of the dye and metal ion solution was adjusted by using $\mathrm{NaOH}$ or $\mathrm{HCl}$ solution. The adsorption studies were carried out at different temperatures $(308,318$ and $328 \mathrm{~K})$. This is used to determine the effect of temperature on the thermodynamic parameters.

The amount of adsorption in batch experiments and adsorption efficiency were calculated as follows:

$$
\mathbf{q}=\left(\mathbf{C}_{\mathbf{0}}-\mathbf{C}_{\mathrm{e}}\right) \mathbf{V} / \mathrm{m}
$$

Efficiency $(\%)=\left(C_{0}-C_{e}\right) / C_{0} \times \mathbf{1 0 0}$

Where, $\mathrm{C}_{\mathrm{o}}$

$\mathrm{C}_{\mathrm{e}} \quad$ is the equilibrium concentration $(\mathrm{mg} / \mathrm{L})$

$\mathrm{V}$ is the volume of solution $(\mathrm{mL})$

$\mathrm{m} \quad$ is the mass of adsorbent $(\mathrm{g})$

$\mathrm{q} \quad$ is the amount of adsorbed $(\mathrm{mg} / \mathrm{g})$

\subsection{Desorption experiments}

It is known that regeneration of adsorbents is an important aspect of adsorption study. In order to determine the reusability of the PCFR, the adsorption-desorption process was repeated three times. 1.0g PCFR adsorbents loaded into $50 \mathrm{ppm}$ of $\mathrm{Pb}(\mathrm{II})$ ion and $\mathrm{MB}$ respectively and added into $100 \mathrm{~mL}$ of $1 \%(\mathrm{v} / \mathrm{v}) \mathrm{HNO}_{3} /$ $0.05 \mathrm{~m}$ of Acetic acid solution for $3 \mathrm{~h}$ at room temperature. The adsorption performance in each cycle was measured. The desorbed dye solution was separated by centrifugation and analyzed as before. The percentage of desorption was calculated. The desorption ratio (E) was calculated as follows:

$E(\%)=C_{d} V_{d} /\left(C_{0}-C_{e}\right) \times 100$

Where $\mathrm{E}$ is the desorption ratio, $\mathrm{C}_{\mathrm{d}}$ is the concentration of the solutes in the desorption solutions, $\mathrm{V}_{\mathrm{d}}$ is the volume of the desorption solution and $\mathrm{C}_{\mathrm{o}}, \mathrm{C}_{\mathrm{e}}$ and $\mathrm{V}$ are the same as defined in Eq. 1 \& 2 .

\subsection{Effect of adsorbent activity}

\section{Results and Discussion}

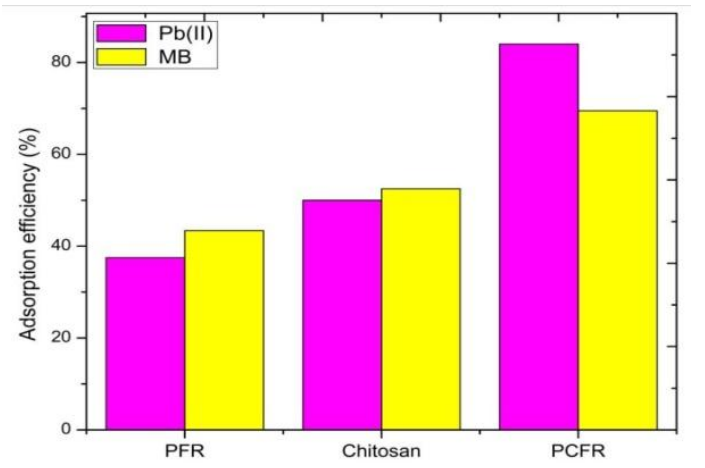

Fig. 1. Adsorbent activity of PFR, Chitosan and PCFR

The activity of adsorbent for the adsorption of $\mathrm{Pb}(\mathrm{II})$ ion and $\mathrm{MB}$ dye was studied with an initial concentration of $20 \& 50 \mathrm{ppm}$, adsorbent dose of $0.2 \mathrm{~g}$ and contact time of $120 \mathrm{~min}$ and the results were displayed in Fig.1. Noticeably as shown in the fig.1, the order of adsorption activity for the removal of $\mathrm{Pb}$ (II) 
ion and MB dye is PCFR > Chitosan > PFR. PCFR composite resin exhibits higher adsorption activity (84\% \& $69.5 \%)$ than Chitosan $(50 \% \& 52.5 \%)$ and PFR resin $(37.5 \% \& 43.4 \%)$ of $\mathrm{Pb}(\mathrm{II})$ and $\mathrm{MB}$ respectively. PCFR composite resin was high removal efficiency than chitosan and PFR resin due to high surface area and facile mass diffusion from the retained interconnected pore system could also be major factors in improving the adsorption potentials.

\subsection{Characterization of the adsorbent}

\section{B.E.T:}

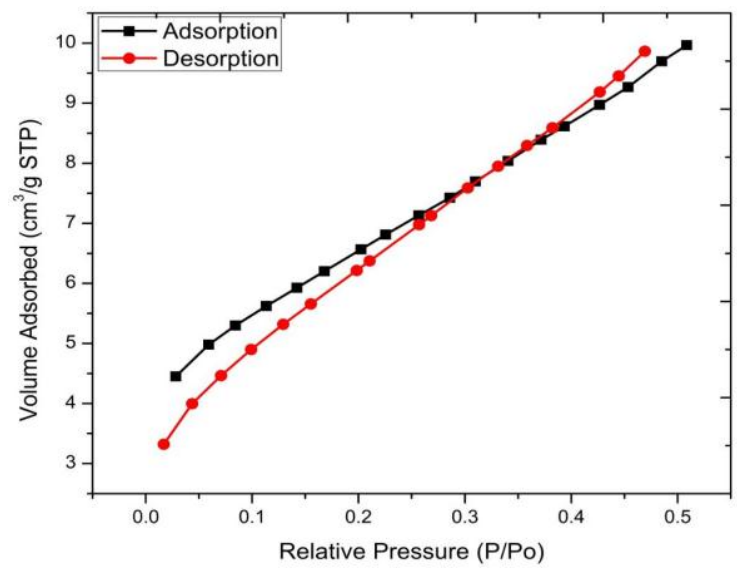

Fig. 2. Adsorption-desorption isotherms of nitrogen at $77 \mathrm{~K}$ on PCFR

The surface area of PCFR was determined by nitrogen sorption measurement. The surface area of PCFR was $26.03 \mathrm{~m}^{2} / \mathrm{g}$. The average pore radius of PCFR was $48.79 \mathrm{~nm}$ and total pore volume was $0.12 \mathrm{~cm}^{3} / \mathrm{g}$ shown in Fig.2. The relative adsorption performance of different adsorbent is highly dependent on the internal pore structure of each material. With the increase of pore radius, more adsorbate is easier to be adsorbed. Therefore carbon activation offered some attractive advantages. It is not only able to increase the surface area and average pore radius but also reinforce the chemical strength of adsorbents in acidic medium.

\section{FTIR:}

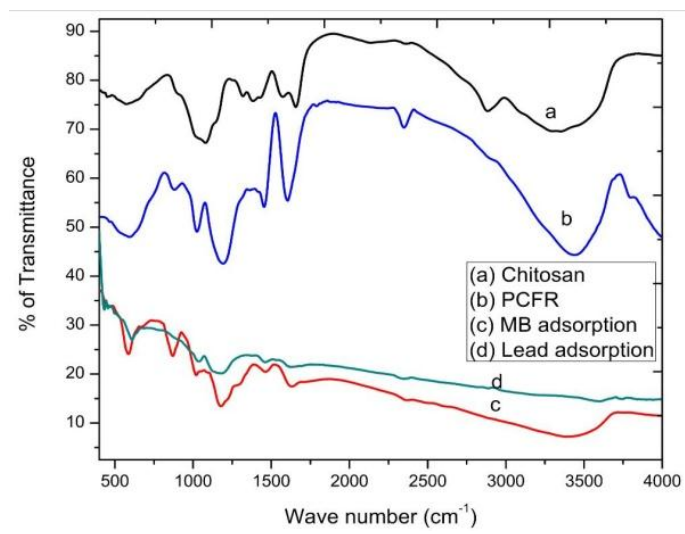

Fig. 3. FTIR spectra of: (a) Chitosan (b) PCFR (c) PCFR-MB (d) PCFR-Pb(II)

FTIR spectra of the Chitosan, PCFR, PCFR-Pb(II) and PCFR-MB were shown in Fig.3. The main bands observed in the IR spectra of Chitosan (Fig. 3a), were the axial stretching of -OH and C-H groups at 3350 and $2907 \mathrm{~cm}^{-1}$ respectively, which appears superimposed to the $\mathrm{N}-\mathrm{H}$ stretching band; $\mathrm{C}=\mathrm{O}$ stretching band (amide I) at $1654.9 \mathrm{~cm}^{-1}, \mathrm{CH}_{3}$ symmetrical angular deformation at $1382.9 \mathrm{~cm}^{-1}$ and $\mathrm{C}-\mathrm{N}$ amino groups axial deformation 1319.3, besides the characteristic polysaccharide bands at $1080.1 \mathrm{~cm}^{-1}$. Fig. $3 \mathrm{~b}$, presented a strong absorption band at $1633.7 \mathrm{~cm}^{-1}$ attributed to the $\mathrm{C}=\mathrm{N}$ vibrations characteristic of azomethine [14] which is not observed in chitosan. The bands at 1469 and $881.4 \mathrm{~cm}^{-1}$ were attributed to the $\mathrm{C}=\mathrm{C}$ and $\mathrm{C}-\mathrm{H}$ stretching in the aromatic ring, respectively. FTIR data showed that new peak observed at $2349.3 \mathrm{~cm}^{-1}$ attributed to $\mathrm{S}-\mathrm{H}$ stretching vibrations (Fig.3c). The peaks observed at 3797.8 and $3435.2 \mathrm{~cm}^{-1}$ were assigned to O-H and N-H bands. It may due to MB adsorption onto PCFR.

FTIR data (Fig.3d), showed that the N-H bending vibration wave number at $1633.7 \mathrm{~cm}^{-1}$ before lead adsorption were shifted to $1649 \mathrm{~cm}^{-1}$ after lead adsorption, suggesting the attachment of lead to nitrogen atoms, 
which reduced the vibration intensity of the $\mathrm{N}-\mathrm{H}$ bond due to molecular weight becoming heavier after lead attachment. Another major change in the transmittance can also be observed at the wave number of $2912 \mathrm{~cm}^{-}$ ${ }^{1}$ after lead adsorption. This band region may be assigned to both $\mathrm{C}-\mathrm{H}$ and $\mathrm{O}-\mathrm{H}$ stretching. As lead ion is unlikely to be attached to a carbon atom, the results may therefore suggest that oxygen atoms in the hydroxyls could also be involved in lead ion adsorption.

XRD:

The XRD patterns as shown in Fig.4 were performed to analyze the crystalline nature. The characteristic $20^{\circ}-30^{\circ}$ peaks of Chitosan are discernible in carbon; these indicate that they are amorphous carbon.

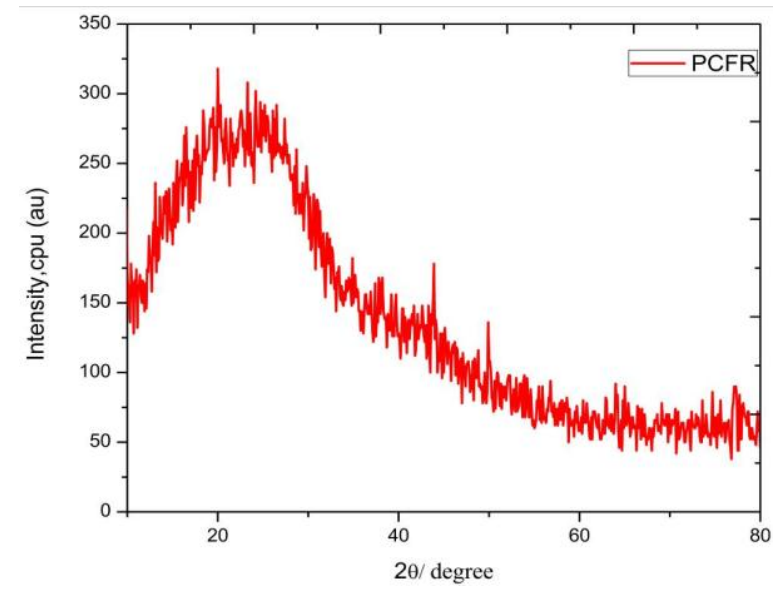

Fig. 4. XRD pattern of PCFR

SEM:

Fig.5, showed the SEMs of PCFR, PCFR-Pb(II) and PCFR-MB dye. However, the particles of PCFR (Fig.5a) are composed of evenly distributed particles. Clearly, there are particle fragments and irregularities structure on the surface. Such cracks and irregularities are beneficial for the metal and dye to diffuse to the inner adsorption sites located in the interior portion of the adsorbent [15]. Fig. 5b and 5c show micrographs of the PCFR surface after adsorbed $\mathrm{Pb}(\mathrm{II})$ ion and $\mathrm{MB}$ dye, which is covered with some small particulates on the surface, suggesting $\mathrm{Pb}(\mathrm{II})$ ion and $\mathrm{MB}$ dye have been adsorbed.
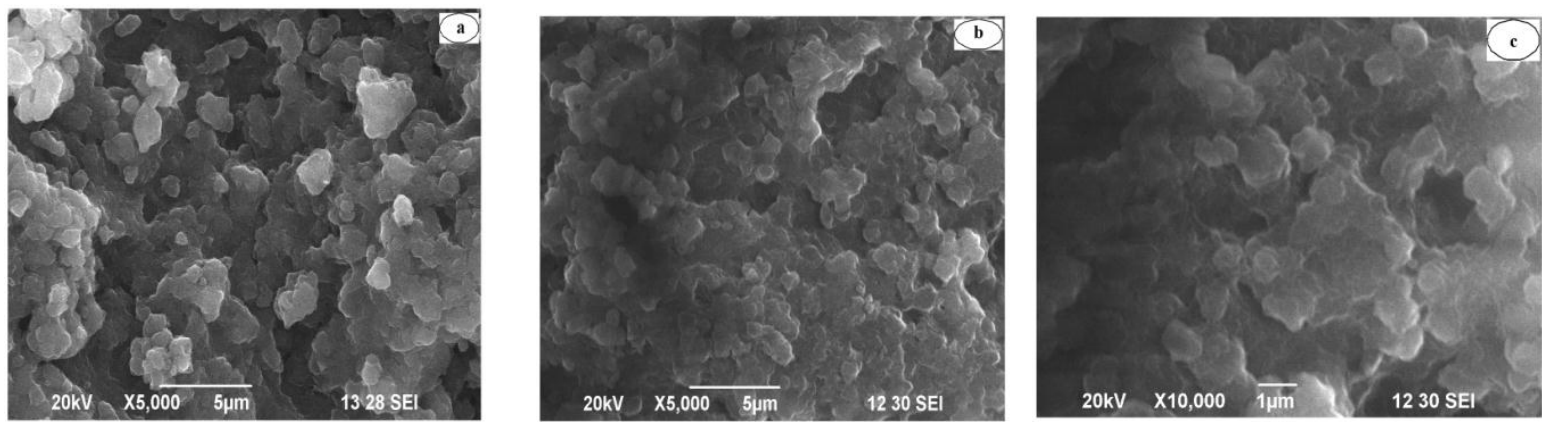

Fig. 5. The SEM images of (a) PCFR (b) PCFR-MB (c) PCFR-Pb(II)

EDX:

Further confirmation of the adsorption of $\mathrm{Pb}$ (II) ion and MB dye on PCFR composite was done by energy dispersive X-ray analysis (EDX). Fig.6a for the unloaded PCFR did not show any characteristic signal for metal ions, only shows that the three major constituents, i.e., C, O and S composition were $59.48 \%, 34.59 \%$, and 5.93\%, respectively. The EDS spectrum (Fig.6b) of after adsorption of $\mathrm{Pb}$ (II) ion presented a new appearing peak at $2.0 \mathrm{keV}$, which is associated to $\mathrm{Pb}$ element. This provided an evidence for $\mathrm{Pb}$ (II) ion adsorption onto PCFR surface. Fig.6c shows three components $\mathrm{C}, \mathrm{O}$ and $\mathrm{S}$ values for the PCFR-MB adsorption composition were $73.18 \%, 25.11 \%$ and $1.71 \%$ respectively. To compare both the (Fig.6a and $6 \mathrm{c}$ ) ' $\mathrm{C}$ ' atomic percentage was increased, due to adsorption of MB dye onto PCFR. 

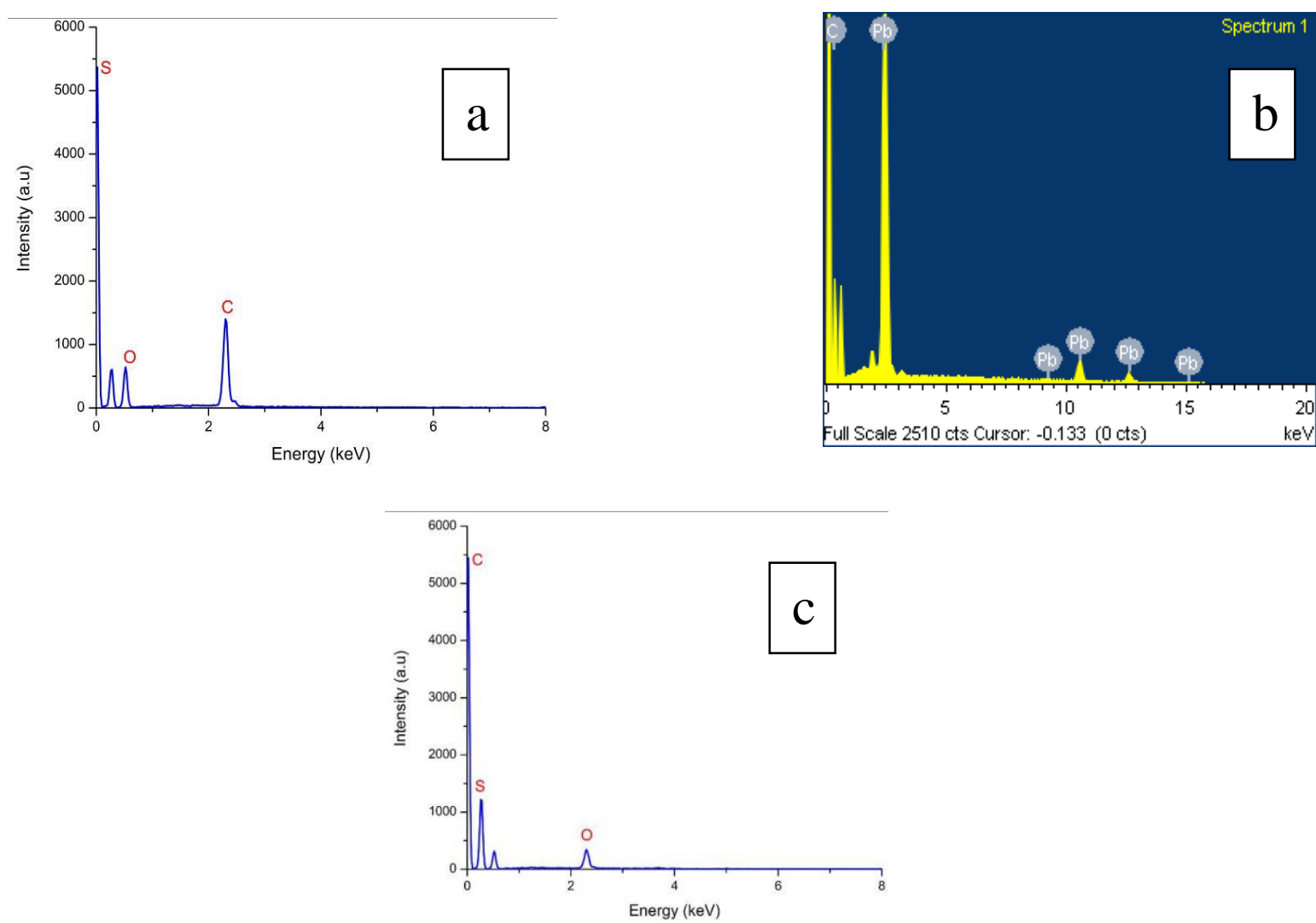

Fig. 6. Energy dispersive spectra of (a) PCFR (b) PCFR-Pb(II) (c) PCFR-MB

TGA:

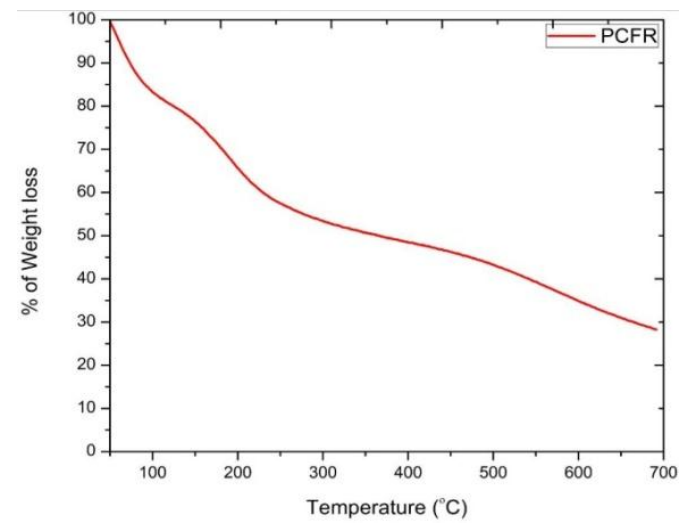

Fig. 7. TGA curve of PCFR

The TGA thermograms for the PCFR samples were shown in Fig.7. The thermo gravimetric profile revealed that the mass loss was occurred in three stages. The first stage at around $50-118{ }^{\circ} \mathrm{C}$, with a mass loss of $18.92 \%$, is related mainly to the loss of water physically adsorbed on the surface of the materials. The second stage showed that the degradation temperature for PCFR was $118-390{ }^{\circ} \mathrm{C}$ with a mass loss of $31.76 \%$. The last weight loss was determined above $390-700{ }^{\circ} \mathrm{C}$, which about $20.64 \%$. Finally, no mass loss was detected when the temperature was increased to $700{ }^{\circ} \mathrm{C}$. This result indicates the PCFR are stable at higher temperature. The char residue of PCFR content was $31 \%$.

The characterization results confirmed that the formation of the adsorbent PCFR occurred successfully.

\subsection{Effect of initial concentrations}

In order to determine the optimum initial concentration of the target metal ion and dye, its value was varied in the range $20-60 \mathrm{mg} / \mathrm{L}$ and $50-120 \mathrm{mg} / \mathrm{L}$ for $\mathrm{Pb}$ (II) ion and $\mathrm{MB}$ dye respectively, while keeping the temperature, sorbent mass and the contact time constant. The effect of initial concentration on the removal of $\mathrm{Pb}(\mathrm{II})$ ion and MB dye by the adsorbent is indicated in Fig.8. 


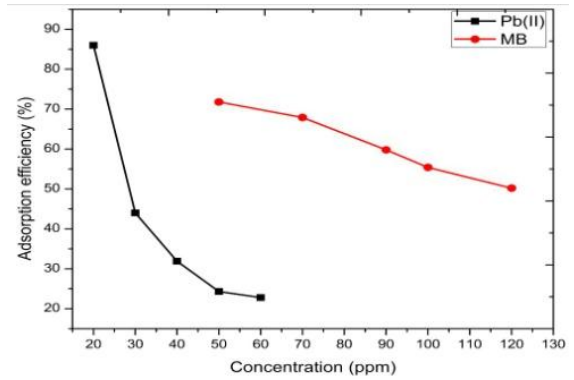

Fig.8. Effect of initial concentrations of $\mathrm{Pb}(\mathrm{II})$ and $\mathrm{MB}$ dye

It is evident from that percentage of $\mathrm{Pb}$ (II) ion and $\mathrm{MB}$ dye removal decreases with increase in concentrations, however actual amount of the $\mathrm{Pb}$ (II) ion and MB dye adsorbed is increased. This is due to increase in concentration, surface area, and active sites of the adsorbent were saturated and hence percentage removal decreases. In this study $\mathrm{Pb}(\mathrm{II})$ ion removal was higher than that of $\mathrm{MB}$ dye.

\subsection{Effect of contact time}

Adsorption was studied at various time intervals (30-240 min) and fixed concentration of $\mathrm{Pb}$ (II) ion was $20 \mathrm{ppm}$ and 50ppm concentration of MB dye. The concentration of $\mathrm{Pb}$ (II) ion and $\mathrm{MB}$ dye was determined at the end of each time. The obtained equilibrium capacities $\left(\mathrm{q}_{\mathrm{e}}\right)$ were then plotted against the equilibrium time (t) for kinetic modeling. All the results were presented in Fig.9. Adsorption increased rapidly with an increase in contact time from 30 to $240 \mathrm{~min}$. A further increase in time had no effect on the adsorption. A maximum contact time of 180 and 120 min was therefore considered as optimum time for $\mathrm{Pb}$ (II) ion and MB dye respectively.

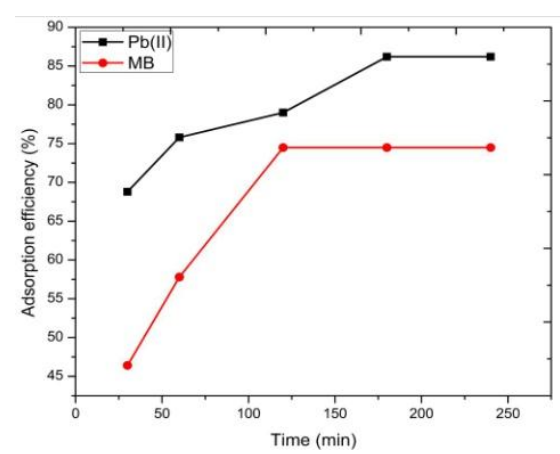

Fig.9. Effect of contact time

\subsection{Effect of adsorbent mass:}

The amount of adsorbent was optimized to obtain the optimal removal. Adsorption experiments were conducted using different amounts of PCFR, likewise $0.050-0.250 \mathrm{~g}$ and $0.010-0.070 \mathrm{~g}$ of $\mathrm{Pb}$ (II) ion and $\mathrm{MB}$ respectively. The initial concentration of $\mathrm{Pb}$ (II) ion $20 \mathrm{ppm}$ and $\mathrm{MB}$ concentration was $50 \mathrm{ppm}$, at room temperature and fixed time. The results are presented in Fig.10.

The results showed that adsorption increased sharply for $\mathrm{Pb}(\mathrm{II})$ ion was 66.7 to $80.3 \%$ with an adsorbent amount of $0.050-0.200 \mathrm{~g}$ and $\mathrm{MB}$ was 45.6 to $73.6 \%$ with an adsorbent amount of $0.010-$ $0.070 \mathrm{~g}$. Thus, 0.150 and $0.050 \mathrm{~g}$ was considered as the optimum adsorbent for the removal of $\mathrm{Pb}$ (II) ion and $\mathrm{MB}$ respectively.

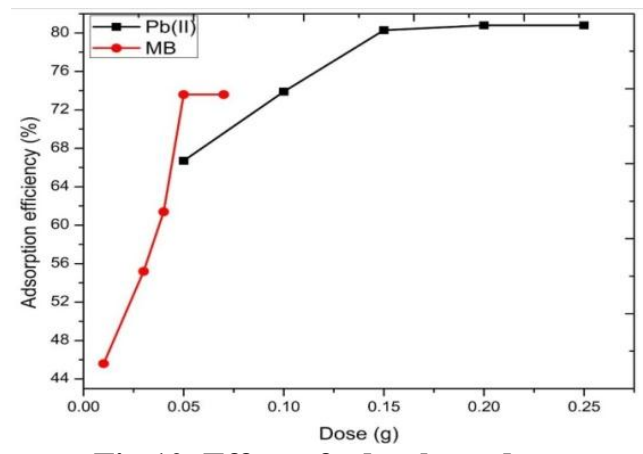

Fig.10. Effect of adsorbent dose 


\section{Adsorption isotherms:}

The adsorption equilibrium data were tested by five isotherm models, namely the Langmuir, Freundlich, Temkin, D-R and Jovanoic isotherm.

Langmuir isotherm [16], which assumes monolayer adsorption onto a homogeneous surface with a finite number of identical adsorption sites, can be represented in a linear form as follows:

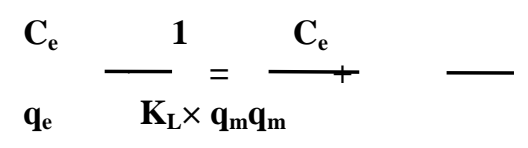

Where, $\mathrm{q}_{\mathrm{m}}$ is the maximum adsorption capacity, $\mathrm{K}_{\mathrm{L}}$ is the Langmuir bonding energy coefficient. The $\mathrm{K}_{\mathrm{L}}$ and $\mathrm{q}_{\mathrm{m}}$ can be calculated from the intercept and slope of the linear plot of $\mathrm{C}_{\mathrm{e}} / \mathrm{q}_{\mathrm{e}}$ against $\mathrm{C}_{\mathrm{e}}$ shown in Fig.11.
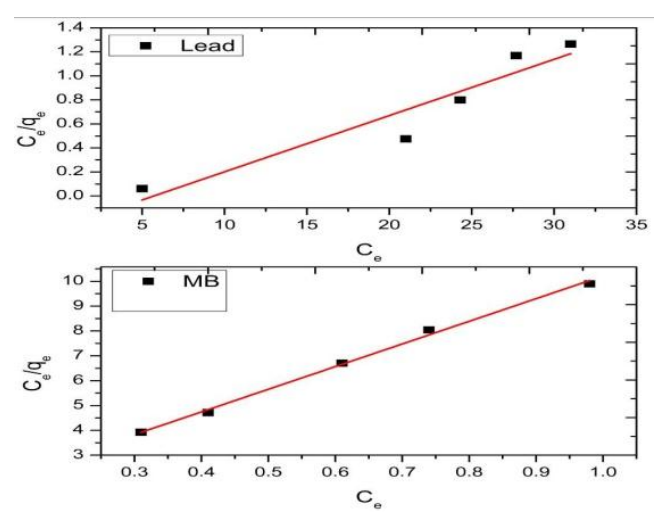

Fig.11. Langmuir isotherm plots for the adsorption of $\mathrm{Pb}(\mathrm{II})$ and $\mathrm{MB}$ onto PCFR

In order to determine if the adsorption process is favorable or unfavorable, a dimensionless constant separation factor or equilibrium parameter $\mathrm{R}_{\mathrm{L}}$ is defined according to the following equation [17]:
$R_{L}=\mathbf{1} / \mathbf{1}+K_{L} C_{0}$

Where, $K_{L}$ is the Langmuir isotherm constant $(\mathrm{L} / \mathrm{mg})$ and $C_{o}$ is the initial dye concentration $(\mathrm{mg} / \mathrm{L})$. The $R_{\mathrm{L}}$ value indicates the type of the isotherm to be either unfavorable $\left(R_{L}>1\right)$, linear $\left(R_{L}=1\right)$, favorable $\left(0<R_{L}<1\right)$, irreversible $\left(R_{L}=0\right)$. The $R_{L}$ value of $M B$ was higher than compare to that of $P b(I I)$ ion. As it is clear from $M B$ all $R_{L}$ of values range between $0.915-0.858$, indicating the favorable adsorption of MB onto PCFR.

Freundlich isotherm [18], which assumes adsorption onto a heterogeneous surface, can be represented in a linear form as follows:

$\log q_{e}=\log K_{F}+1 / n \log C_{e}$

Where, qe is the amount of dye and metal ion adsorbed at equilibrium (in $\mathrm{mg} / \mathrm{g}$ ), and $\mathrm{C}_{\mathrm{e}}$ is the $\mathrm{MB}$ and $\mathrm{Pb}(\mathrm{II})$ ion concentration in solution at equilibrium (in $\mathrm{mg} / \mathrm{L}$ ). $\mathrm{K}_{\mathrm{F}}$ and $\mathrm{n}$ are Freundlich constants which indicate capacity and heterogeneity factor. The value of $\mathrm{n}$ ranged from 0 to 1 , and $\mathrm{n}$ value closer to 1 indicates high surface heterogeneity. The $\mathrm{K}_{\mathrm{F}}$ and $\mathrm{n}$ can be calculated from the intercept and slope of the linear plot of $\log \mathrm{q}_{\mathrm{e}}$ against $\log \mathrm{C}_{\mathrm{e}}$.

Temkin isotherm [19], which assumes that the heat of adsorption of all the molecules in the layer decreases linearly with coverage due to adsorbent-adsorbate interactions and characterized by a uniform distribution of binding energy, can be represented in a linear form as follows:

$$
q_{e}=B_{1} \ln K_{T}+B_{1} \ln C_{e}
$$

Where, $\mathrm{B}_{1}$ and $\mathrm{K}_{\mathrm{T}}$ are constants, representing adsorption capacity and retention intensity of adsorption. The $\mathrm{B}_{1}$ and $\mathrm{K}_{\mathrm{T}}$ can be calculated from the intercept and slope of the linear plot of $\mathrm{q}_{\mathrm{e}}$ against $\ln \mathrm{C}_{\mathrm{e}}$.

In order to determine the type of adsorption, D-R isotherm has also been tested for the adsorption of both $\mathrm{MB}$ and $\mathrm{Pb}(\mathrm{II})$ ion onto PCFR. The D-R equation can be defined by the following equation [20].

$$
\operatorname{lnq}_{\mathrm{e}}=\ln \mathrm{q}_{\mathrm{m}}-\boldsymbol{\beta} \varepsilon^{2}
$$

Where, $\beta$ a constant related to the adsorption energy $\left(\mathrm{mol}^{2} / \mathrm{kJ}^{2}\right), \mathrm{q}_{\mathrm{m}}$ is a constant that indicates the sorption degree characterizing the sorbent $(\mathrm{mg} / \mathrm{g})$ and $\varepsilon$ is the Polanyi potential shown in Eq. 8:

$$
\varepsilon=R T \ln \left(1+1 / C_{e}\right)
$$

Where, $\mathrm{T}$ is the absolute temperature $(\mathrm{K})$ and $\mathrm{R}$ is the ideal gas constant $(\mathrm{R}=8.314 \mathrm{~J} / \mathrm{mol} / \mathrm{K})$. 

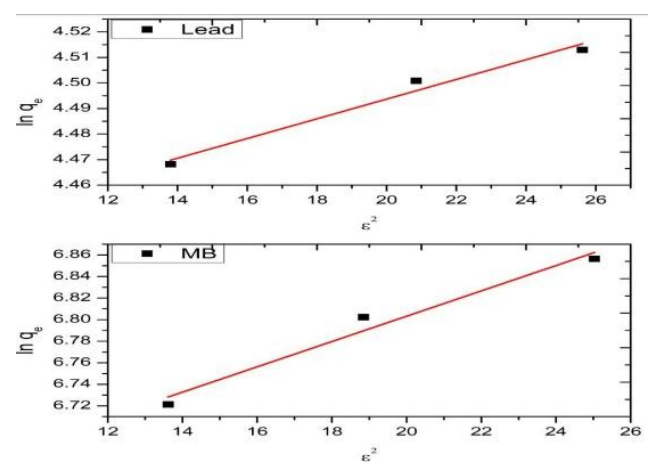

Fig.12. D-R isotherm plots for the adsorption of Pb(II) and MB onto PCFR

By plotting $\ln q_{\mathrm{e}}$ versus $\varepsilon^{2}$ (Fig.12), it is possible to determine the value of $\beta$ from the slope and the value of $\mathrm{q}_{\mathrm{m}}$ from the intercept, which is $\operatorname{lnq}_{\mathrm{m}}$.

The mean free energy $\mathrm{E}(\mathrm{kJ} / \mathrm{mol})$ of sorption can be estimated by using $\beta$ values as expressed in the following equation [21].

$$
E=1 /(2 \beta)^{1 / 2}
$$

The magnitude of $E$ may characterize the type of the adsorption as chemical ion exchange $(E=8-16 \mathrm{~kJ} / \mathrm{mol})$, or physical adsorption $(\mathrm{E}<8 \mathrm{~kJ} / \mathrm{mol})$. The mean free energy of adsorption for the present study was found to be $\mathrm{Pb}$ (II) ion has 12.9 and $\mathrm{MB}$ was $6.79 \mathrm{~kJ} / \mathrm{mol}$. This implies that, the adsorption of $\mathrm{Pb}$ (II) ion on PCFR may be considered as chemical adsorption process, the MB was physical adsorption process.

The Jovanoic isotherm [22], which is based on the same assumptions of the Langmuir isotherm, also considers the possibility of some mechanical contacts between the adsorbing and desorbing molecules on the homogeneous surface and can be represented in a linear form as follows:

$$
\ln q_{e}=\ln q_{m}+K_{J} C_{e}
$$

Where, $\mathrm{q}_{\mathrm{m}}$ is the maximum amount adsorbed (in $\mathrm{mg} / \mathrm{g}$ ) and $\mathrm{K}_{\mathrm{J}}$ (in $\mathrm{L} / \mathrm{mg}$ ) is the constant related to the energy of adsorption. The $\mathrm{q}_{\mathrm{m}}$ and $\mathrm{K}_{\mathrm{J}}$ can be calculated from the intercept and slope of the linear plot of $\operatorname{lnq}_{\mathrm{e}}$ against $\mathrm{C}_{\mathrm{e}}$.

To understand the adsorption equilibrium behavior, five isotherms, namely Langmuir, Freundlich, Temkin, D-R and Jovanoic isotherm models were tested, and the Table.1 summarizes the isotherm parameter values. The best fitted models are selected on the basis of coefficient Langmuir isotherm and D-R isotherm model. The Langmuir isotherms were best fit model for the adsorption of MB, The maximum adsorption capacity of MB was $10.96 \mathrm{mg} / \mathrm{g}$. The D-R isotherm model well described in both $\mathrm{Pb}$ (II) ion and MB onto PCFR. The maximum amount adsorbed was 260.6 and $369.8 \mathrm{mg} / \mathrm{g}$ for $\mathrm{Pb}$ (II) ion and MB respectively.

Table 1. Different adsorption isotherm model parameters for the adsorption of Pb(II) and MB on PCFR

\begin{tabular}{llll}
\hline \multicolumn{1}{c}{ Mathematical models } & parameters & Pb(II) ion & MB \\
\hline Langmuir isotherm & $\mathrm{R}^{2}$ & 0.901 & 0.996 \\
& $\mathrm{~K}_{\mathrm{L}}$ & $1.723 \times 10^{-3}$ & $8.35 \times 10^{-4}$ \\
\multirow{3}{*}{ Freundlich isotherm } & $\mathrm{q}_{\mathrm{m}}(\mathrm{mg} / \mathrm{g})$ & 21.73 & 10.96 \\
& $\mathrm{R}^{2}$ & 0.899 & 0.942 \\
& $\mathrm{~K}_{\mathrm{F}}$ & $331.1 \times 10^{3}$ & $787.0 \times 10^{4}$ \\
\multirow{5}{*}{ Temkin isotherm } & $\mathrm{n}$ & 1.517 & 5.7142 \\
& $\mathrm{R}^{2}$ & 0.968 & 0.840 \\
D-R isotherm & $\mathrm{B}_{1}$ & 32.3 & 0.101 \\
& $\mathrm{~K}_{\mathrm{T}}$ & 135.4 & 6.497 \\
& $\mathrm{R}^{2}$ & 0.978 & 0.974 \\
\multirow{5}{*}{ Jovanoic isotherm } & $\beta$ & 0.003 & 0.011 \\
& $\mathrm{q}_{\mathrm{m}}(\mathrm{mg} / \mathrm{g})$ & $260.6 \times 10^{2}$ & $369.8 \times 10^{4}$ \\
& $\mathrm{E} \mathrm{kJ} / \mathrm{mol}$ & 12.9 & 6.74 \\
& $\mathrm{R}^{2}$ & 0.954 & 0.902 \\
& $\mathrm{~K}_{\mathrm{J}}(\mathrm{L} / \mathrm{mg})$ & 0.050 & 0.296 \\
& $\mathrm{q}_{\mathrm{m}}(\mathrm{mg} / \mathrm{g})$ & 4.689 & 6.614 \\
\hline
\end{tabular}

\section{Kinetic Studies:}

The applicability of the pseudo-first-order model, pseudo-second-order model and Intra particle diffusion model was investigated to identify the mechanism of $\mathrm{Pb}$ (II) ion and MB adsorption on PCFR as follows:

\subsection{Pseudo-first-order mode:}

The Lagergren pseudo-first-order model illustrated the adsorption kinetic data, which is the earliest known equation describing the adsorption rate based on the adsorption capacity. The integral form of the pseudo-first-order model is generally expressed as [23] 
$\ln \left(\mathbf{q}_{\mathrm{e}^{-}} \mathbf{q}_{\mathrm{t}}\right)=\ln \mathbf{q}_{\mathrm{e}}-\mathrm{k}_{\mathbf{1}} \mathrm{t}$

Where, $\mathrm{k}_{1}(\mathrm{~L} / \mathrm{min})$ and predicted $\mathrm{q}_{\mathrm{e}}$ can be determined from the slope and intercept of the linear plot between $\mathrm{ln}$ $\left(\mathrm{q}_{\mathrm{e}}-\mathrm{q}_{\mathrm{t}}\right)$ and $\mathrm{t}$, respectively.

\subsection{Pseudo-second-order model:}

The adsorption kinetic may be described by the pseudo-second-order model. The differential equation is generally known and described as [24].

$$
\frac{\mathrm{t}}{\mathrm{q}_{\mathrm{t}}}=\frac{1}{\mathrm{k}_{2} \mathrm{q}_{\mathrm{e}}^{2} \mathrm{q}_{\mathrm{e}}}+\stackrel{1}{-}
$$

Where, $\mathrm{k}_{2}(\mathrm{~g} / \mathrm{mg} / \mathrm{min})$ is the second-order rate constant of adsorption. The plot of $\mathrm{t} / \mathrm{q}_{\mathrm{t}}$ versus $\mathrm{t}$ shows a linear relationship. Values of $\mathrm{k}_{2}$ and equilibrium adsorption capacity $\mathrm{q}_{\mathrm{e}}$ were calculated from the intercept and slope of the plot shown in Fig.13.

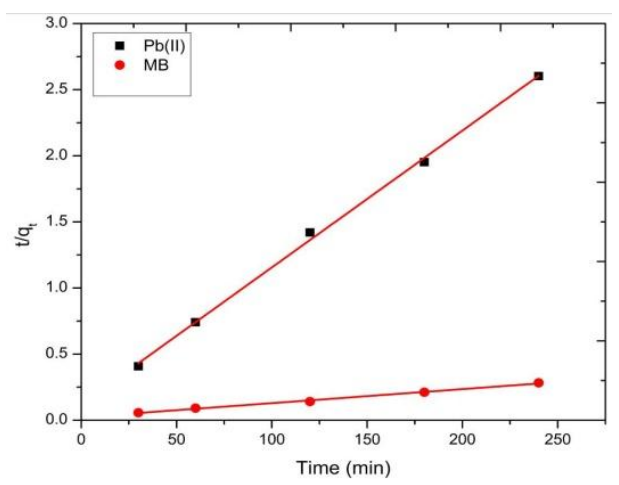

Fig. 13. Pseudo-second-order kinetic plots for adsorption of $\mathrm{Pb}(\mathrm{II})$ ion and MB onto PCFR 5.3 Intra-particle diffusion model:

The adsorption proceeds in several steps involving transport of solute molecules from the aqueous phase to the surface of the solid particles and then interior of the solid. According to [25], for most adsorption processes the amount of adsorption varies almost proportional with $\mathrm{t}_{1 / 2}$, which can be expressed as

$\mathbf{q}_{\mathrm{t}}=\mathbf{k}_{\mathrm{id}} \mathbf{t}^{0.5}+\mathbf{C}$

Where, $\mathrm{q}_{\mathrm{t}}$ is the adsorption capacity at time $\mathrm{t}, \mathrm{t}^{0.5}$ is the half life time in second and $\mathrm{k}_{\mathrm{id}}\left(\mathrm{mg} / \mathrm{g} / \mathrm{min}^{0.5}\right)$ is the rate constant of the intra-particle diffusion model and $\mathrm{C}(\mathrm{mg} / \mathrm{g})$ reflects the boundary layer effect. The $\mathrm{k}_{\mathrm{id}}$ and $\mathrm{C}$ can be determined from the slope and intercept of the linear plot of $\mathrm{q}_{\mathrm{t}}$ against $\mathrm{t}^{0.5}$.

Table 2. Kinetic parameters for the adsorption of $\mathrm{Pb}(\mathrm{II})$ ion and Methylene blue dye on PCFR

\begin{tabular}{llll}
\hline \multicolumn{1}{c}{ Mathematical models } & parameters & $\mathbf{P b}(\mathbf{I I})$ ion & MB \\
\hline First-order kinetics & $\mathrm{R}^{2}$ & 0.735 & 0.246 \\
& $\mathrm{k}_{1}\left(\mathrm{~min}^{-1}\right)$ & 0.007 & 0 \\
& $\mathrm{q}_{\mathrm{e}}(\mathrm{mg} / \mathrm{g})$ & 10.11 & 209.4 \\
Second-order kinetics & $\mathrm{R}^{2}$ & 0.998 & 0.996 \\
& $\mathrm{k}_{2} \mathrm{~g} / \mathrm{mg} / \mathrm{min}$ & 0.0833 & 0.0454 \\
& $\mathrm{q}_{\mathrm{e}}(\mathrm{mg} / \mathrm{g})$ & 100 & 1000 \\
Intra-particle diffusion & $\mathrm{R}^{2}$ & 0.946 & 0.835 \\
& $\mathrm{k}_{\text {id }} \mathrm{g} / \mathrm{mg} / \mathrm{min}^{1 / 2}$ & 1.885 & 32.99 \\
& $\mathrm{C}(\mathrm{mg} / \mathrm{g})$ & & 397.6 \\
\hline
\end{tabular}

The pseudo-first-order, pseudo-second-order and intra-particle diffusion models were used to understand the kinetic nature of $\mathrm{Pb}(\mathrm{II})$ ion and MB onto PCFR adsorption system. All the values are presented in Table.2. Based on linear regression $\left(\mathrm{R}^{2}\right)$ values, the kinetics of $\mathrm{Pb}(\mathrm{II})$ ion and $\mathrm{MB}$ adsorption onto the PCFR can be described well by second-order equation. The value of pseudo-second-order rate constant, $\mathrm{k}_{2}$, for $\mathrm{Pb}(\mathrm{II})$ ion was 0.0833 and $\mathrm{MB}$ was $0.0454 \mathrm{~g} / \mathrm{mg} / \mathrm{min}$.

VI.

\section{thermodynamic data}

\section{Effect of temperature and}

The adsorption tests were performed by batch technique in single system at $308 \mathrm{~K}, 318 \mathrm{~K}$ and $328 \mathrm{~K}$ respectively. For kinetic studies, a series of $250 \mathrm{ml}$ flask were used and each flask was filled with PCFR at mass 
loadings $0.150 \mathrm{~g}$ for $\mathrm{Pb}(\mathrm{II})$ ion solution and $0.050 \mathrm{~g}$ for $\mathrm{MB}$ solution at $20 \mathrm{ppm}$ and $50 \mathrm{ppm}$ initial concentrations respectively. The percentage removal of $\mathrm{Pb}(\mathrm{II})$ ion and $\mathrm{MB}$ are presented in Fig.14.

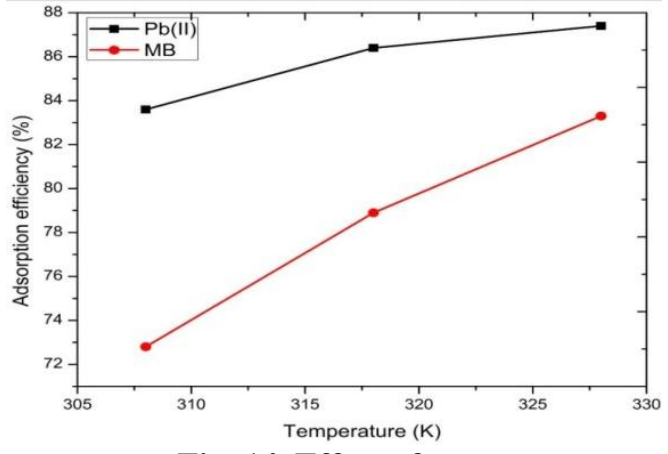

Fig. 14. Effect of temperature

The energy and entropy considerations are very important in order to understand the kinetics of adsorption. The amount of $\mathrm{Pb}(\mathrm{II})$ ion and $\mathrm{MB}$ adsorbed at equilibrium at different temperature has examined to obtain the thermodynamic parameters. The $\mathrm{K}_{\mathrm{L}}$ value is used in the following equation to determine the change of Gibbs free energy of adsorption $\left(\Delta G^{\circ}\right)$.

$$
\mathbf{K}_{\mathbf{L}}=\frac{\mathbf{q}_{\mathbf{e}}}{\mathbf{C}_{\mathrm{e}}}
$$

$\Delta G^{\circ}=-R T \ln K_{L}$

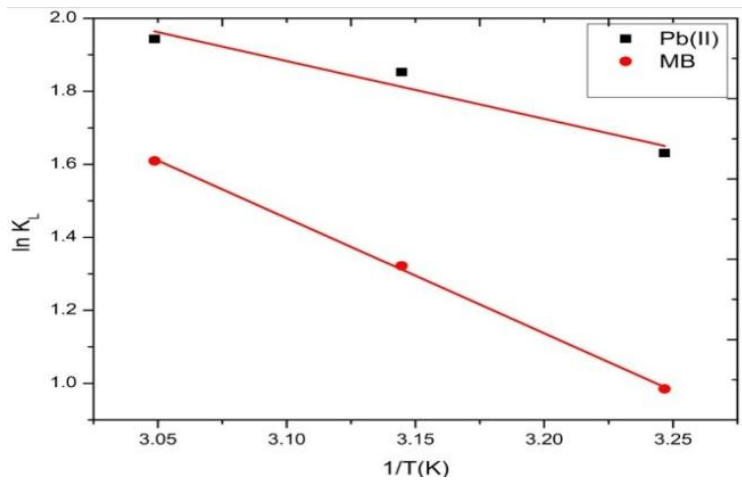

Fig. 15.van't Hoff plots of $\ln K_{L}$ versus 1/T for the adsorption of $\mathrm{Pb}(\mathrm{II})$ ion and MB onto PCFR

The change in enthalpy $\left(\Delta \mathrm{H}^{\circ}\right)$ and entropy $\left(\Delta \mathrm{S}^{\circ}\right)$ was determined from the slope and intercept of van't Hoff plot of $\ln \mathrm{K}_{\mathrm{L}}$ versus $1 / \mathrm{T}$ plot (Fig.5.15), according to the following equation:

$\Delta \mathbf{S}^{\circ} \Delta \mathbf{H}$

$\ln K_{L}=\underset{R}{R T}$

Where, $\mathrm{K}_{\mathrm{L}}$ is

Langmuir

Where $\mathrm{R}$ is

constant

$\mathrm{K})$, $\mathrm{T}$ is the

(in $\mathrm{K}$ ). The

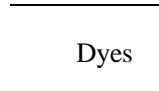

$\overline{\mathrm{R}^{2}}$

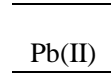

\begin{tabular}{ll}
\hline $\mathrm{R}^{2}$ & $\Delta \mathrm{H}^{\circ}$ \\
$\mathrm{J} / \mathrm{mol}$
\end{tabular}
Thermodynamics parameters

$\Delta \mathrm{S}^{\circ}$
$\mathrm{J} / \mathrm{mol} \mathrm{K}$

0.952

13.44

64.56

$\frac{308 \mathrm{~K}}{66.88}$
$-\Delta \mathrm{G}^{\circ}(\mathrm{k}$

$318 \mathrm{~K}$

$328 \mathrm{~K}$

thermodynamic parameters are presented in Table 3. the constant. the gas (8.314 J/mol temperature estimated 


\begin{tabular}{lllllll}
\hline MB & 1 & 24.84 & 146.4 & 202.9 & 217.5 & 232.2 \\
\hline
\end{tabular}

Table.3.Thermodynamic parameters for the adsorption of $\mathrm{Pb}(\mathrm{II})$ ions and MB dye on PCFR

The correlation coefficient for the linear plot for $\mathrm{Pb}(\mathrm{II})$ ion and $\mathrm{MB}$ was $\mathrm{R}^{2}=0.952$ and $\mathrm{R}^{2}=1$ respectively. The negative values of $\Delta \mathrm{G}^{\circ}$ at all temperatures indicate the spontaneous nature of the adsorption of $\mathrm{Pb}$ (II) ion and $\mathrm{MB}$ on PCFR. The $\Delta \mathrm{G}^{\circ}$ was negative and increased towards negative side with rise in temperature, indicating the adsorption process to be spontaneous in nature without any induction period and more favorable at higher temperature.

The standard enthalpy and entropy changes of adsorption determined from the Eq. (17) were 13.14 $\mathrm{kJ} / \mathrm{mol}$ and $64.56 \mathrm{~J} / \mathrm{mol} / \mathrm{K}$ for $\mathrm{Pb}(\mathrm{II})$ ion, $24.84 \mathrm{~kJ} / \mathrm{mol}$ and $146.49 \mathrm{~J} / \mathrm{mol} / \mathrm{K}$ for $\mathrm{MB}$, respectively. The positive value of $\Delta \mathrm{H}^{\circ}$ suggests the endothermic nature of adsorption. The positive value of $\Delta \mathrm{S}^{\circ}$ confirmed the increased randomness at the solid-solute interface during adsorption process, which suggests that $\mathrm{Pb}(\mathrm{II})$ ion and $\mathrm{MB}$ replace some water molecules from the solution previously adsorbed on the surface of adsorbent. These displaced molecules gain more translation entropy than lost by the adsorbate ions, thus allowing the prevalence of randomness in the system [26].

\section{Desorption studies:}

An important characteristic of adsorbents is the desorption efficiency. The results show that the amounts of $\mathrm{Pb}$ (II) ion and MB adsorbed on PCFR from three repeated adsorption-desorption cycles. It is found that the adsorbents can be used repeatedly without changing significantly their adsorption capacities with high desorption percentages $98 \%$ for $\mathrm{Pb}$ (II) ion and $\mathrm{MB}$ studied here.

\section{Conclusion:}

This study showed the characterization of PCFR and Pb (II) ion and MB adsorption behavior by PCFR. The PCFR was mainly composed of hydroxyl, esters and secondary cyclic alcohols on the surface of PCFR. The equilibrium adsorption can be fitted by Langmuir for $\mathrm{MB}$ and $\mathrm{D}-\mathrm{R}$ isotherm for both $\mathrm{Pb}(\mathrm{II})$ ion and $\mathrm{MB}$ adsorption. The kinetic process can be predicted by pseudo-second-order model. The adsorption may be controlled by external mass transfer followed by intra-particle diffusion mass transfer. The thermodynamics parameters indicated spontaneous and endothermic process. The treated PCFR are much effective adsorption for $\mathrm{Pb}(\mathrm{II})$ ion but less adsorption in MB.

\section{Reference:}

[1]. E.S. Abdel-Halim and Salem S. Al-Deyab, Carbohydr. polym. 84 (2011) 454-458.

[2]. A. Bhatnagar, A.K. Jain, J. Colloid Interf. Sci. 28 (2005) 49-55.

[3]. A. Balarial, S. Schiewer, Sep. Purif. Technol. 63 (2008) 577-581.

[4]. S. Bhattacharjee, S. Chakrabarty, S. Maity, Water Res. 37 (2003) 3954-3966.

[5]. B.S. Inbaraj, J.T. Chien, G.H. Ho, J. Yang, B.H. Chen, Biochem. Eng. 31 (2006)204-215.

[6]. M.M.M. Goncalves, A.C.A. Da costa, S.G.F. Leite, and G.L. Sant' Anna Jr, Chemosphere. 68 (2007) 1815-1820.

[7]. H. Bessbousse, T. Rhlalou, J.F. Verchore and L. Lebrun, Matrix Journal of Membrane Science. 307 (2008) $249-259$.

[8]. N. Dameshvar, H.A. Sorkhabi, M.B. Kasiri, J. Hazard. Mater. B112 (2004) 55-62.

[9]. C. Suksaroj, M.Heran, C. Allegre, F. Persin, Desalination. 178 (2005) 333-341.

[10]. G. Crini, Bioresour. Technol. 97 (2006) 1061-1085.

[11]. L. Wang, J. Hazard. Mater. 147 (2007) 979-985.

[12]. S.L. Won, H.C. Lee, Y.G. Jeong, B.G. Min, and S.C. Lee, Fiber and Polymer. 10 (2009) 636-642.

[13]. H.Y. Zhu, R. Jiang, and J. Xiao, J.ColloidInterf. Sci. 345 (2010) $154-159$.

[14]. M. Monier, D.M. Ayed, B.Y. wei, A.A. Sarhan, React. Funct.Polym. 70 (2010) 257-266.

[15]. T.S. Anirudhan, M.R. Unnithan, L. Divya and P. Senan, J. Appl. Poly. Sci. 104 (2007) 3670-3681

[16]. I. Langmuir, J. Am. Chem. Soc. 40 (1918) 1361-1368.

[17]. M.C. Somasekhara Reddy, L. Sivaramakrishna and A. Varada Reddy, J. Hazard. Mater. 203-204 (2012) 118-127,

[18]. H. Freundlich, Physical Chemical Society. 40 (1906) 1361-1368.

[19]. M.J. Temkin, and V. Pyzhev, ActaPhysiochim URSS. 12 (1940) 217-222.

[20]. M.M. Dubinin, L.V. Radushkevich, Proc. Acad. Sci. VSSR. 55 (1947)331-333.

[21]. S.M. Hansany, M.H. Chaudhary, Appl. Radiation and Isotop. 47 (1996) 467-471.

[22]. D.S. Jovanoic, Colloid and Polymer Science. 235 (1969) 1203-1214.

[23]. M. Dogan, M. Alkan, A.I. Turkyilmaz, Y. Ozdemir, J. Hazard Mater. 109 (2004) 141-148.

[24]. T. Santhi, S. Manonmani, T. Smitha, D. Sugirtha, K. Mahalakshmi, J. Appl. Sci.Environ Sanit. 4 (2009) 29-35.

[25]. W. Weber, J. Morris, J. SanitEngDiv Am. Soc. Civ. Eng. 89 (1963) 31-60.

[26]. E. Malkoc, and Y. Nuhoglu, Chemical Engineering Process. 46 (2007) 1020-1029. 